\title{
Methods of Game Theory in Safe Maritime Transport
}

\author{
Józef Lisowski* \\ Gdynia Maritime University, Poland
}

Submission: August 17, 2018; Published: September 06, 2018

*Corresponding author: Józef Lisowski, Gdynia Maritime University, Poland, Email: j.lisowski@we.am.gdynia.pl

\section{Introduction}

Taking into consideration the form of the quality index the problems of optimal control of the maritime objects may be split into three groups, for which the cost of the process course: is a univocal control function, depends on the way of control and also on a certain random event of a known statistical description and is defined by a choice of the control method and by a certain indefinite factor of an unknown statistical description. The last group of the problems refers to game control systems the synthesis of which is performed by using methods of the games theory.

\section{Classification of Games}

The following types of games can be discriminated:

A. With regard to the number of players: two-person and n-person,

B. With regard to the strategy sets: finite and infinite,

C. With regard to the nature of co-operation: noncoalition, co-operative - through the relationships established earlier and coalition ones,

D. With regard to the nature of the prize: zero-sum closed with a saddle point determined by the optimal pure strategies and those of any sum, e.g.: international trade,

E. With regard to their form of the goal function: matrix, non-continuous and convex,

F. With regard to the nature of conducting the game: in the normal form - one-step static ones and in the extensive form as multi-step games determined by a sequence of movements executed alternately within the kinematical and dynamical processes, the games in their extensive form are split into: positional, stochastic and differential,

G. With regard to the nature of information: with complete and incomplete information,

H. With regard to the to the kind of an opponent: with a thinking opponent and with the nature - the environment performing random movements and not interested in the final result of the game.

\section{Differential games in control engineering}

Three classes of the control problems may be discriminated which may offer possibilities to use the differential games both for the description and synthesis of the optimal control:

a. control of the object with no information available on the disturbances operating on such an object. In this case we have only the state equations of the object and a set of acceptable steering actions. Such a control should be then determined as to ensure the minimal functional, under a condition that the disturbance tends to its maximum; in this case the differential game should be solved with a min max optimum condition,

b. control of the object encountering a greater number of the moving objects of different quality index and final goals. An example, in this case, may be a process of ship control in collision situations when encountering a greater number of the moving or non-moving objects (vessels, underwater obstructions, shore line, etc.) a differential game with many participants,

c. synthesis of the multi-layer hierarchical systems. One of the essential hierarchical languages for the steering systems of various nature and methods of determining optimal control is the theory of games including common interests and the right to the first turn.

\section{Game control processes in marine navigation}

The classical issues of the theory of the decision process in marine navigation include the safe control of a ship. The problem of non-collision strategies in the control at sea developed by many authors both within the context of the game theory, and also in the steering under uncertainty conditions.

The definition of the problem of avoiding a collision seems to be quite obvious, however, apart from the issue of the uncertainty of information which may be a result of external factors (weather conditions, sea state), incomplete 
knowledge about other objects and imprecise nature of the recommendations concerning the right of way contained in International Regulations for Preventing Collision at Sea COLREG. The problem of determining safe strategies is still an urgent issue as a result of an ever increase traffic of vessels on particular water areas. It is also important due to the increasing requirements as to the safety of shipping and environmental protection, from one side, and to the improving opportunities to use computer supporting the navigator's duties.

\section{Differential game of maritime object process control}

In order to ensure safe navigation, ships are obliged to observe legal requirements contained in the COLREG Rules. However, these Rules refer exclusively to two ships under good visibility conditions, in case of restricted visibility the Rules provide only recommendations of general nature and they are unable to consider all necessary conditions of the real process. The real process of the ships passing exercises occurs under the conditions of indefiniteness and conflict accompanied by an imprecise co-operation among the ships in the light of the legal regulations. Consequently, it is reasonable - for ship operational purposes - to present this process and to develop and examine methods for a safe steering of the ship by applying the rules of the game theory.

A necessity to consider simultaneously the strategies of the encountered objects and the dynamic properties of the ships as the control objects is a good reason for the application of the differential game model for the description of the processes.

\section{Types of game object control}

Assuming that the dynamic movement of the maritime objects in time occurs under the influence of the appropriate sets of control $\left[S_{0}^{\left(\delta_{0}\right)}, S_{j}^{\left(\delta_{j}\right)}\right]$, where:

$S_{0}^{\left(\delta_{0}\right)}$ - a set of the own object strategies, as a possible change in the value of the course and the speed of its own object,

$S_{j}^{\left(\delta_{j}\right)}$ - a set of the j-th object strategies, as a possible change in the value of the course and the speed of its j-th object,

$\delta\left(\delta_{0}, \delta_{j}\right)=0$ - denotes course and trajectory stabilisation,

$\delta\left(\delta_{0}, \delta_{j}\right)=1$ - denotes the execution of the anti-collision manoeuvre in order to minimize the risk of collision, which in practice is achieved by satisfying the following inequality: $D_{j, \text { min }}=\min D_{j}(t) \geq D_{s}$, where:

$D_{j, \min }$ - the smallest distance of approach of the own ship and the $\mathrm{j}$-th encountered object,

Ds - safe approach distance in the prevailing conditions depends on the visibility conditions at sea, the COLREG Rules and the object dynamics,

$\mathrm{Dj}$ - current distance to the j-th object taken from the ARPA anti-collision system,

$\delta\left(\delta_{0}, \delta_{j}\right)=-1$ - refers to the manoeuvring of the object in order to achieve the closest point of approach, for example during the approach of a rescue vessel, transfer of cargo from ship to ship, destruction the enemy's ship (Figure 1).

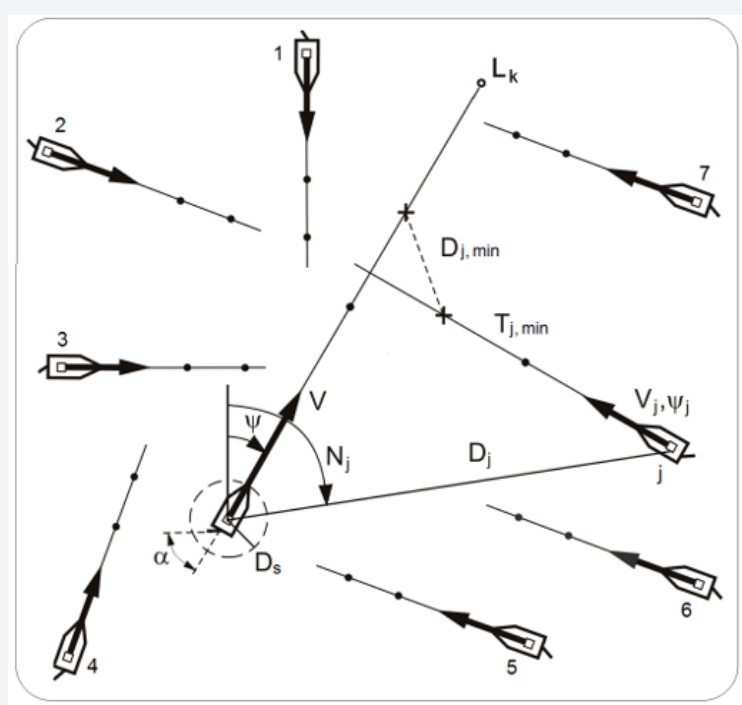

Figure 1: State variables describing the navigational situation during passing of own ship with $\mathrm{j}$-th encountered maritime object.

In the adopted describing symbols, we can discriminate the following type of object control in order to achieve a determined goal:

A. basic type of control - stabilization of the course or trajectory: $\left[\mathrm{S}_{0}^{(0)} \mathrm{S}_{\mathrm{j}}^{(0)}\right]$
B. avoidance of a collision by executing:

a. own ship's manoeuvres: $\left[S_{0}^{(1)} S_{j}^{(0)}\right]$,

b. manoeuvres of the j-th ship: $\left[S_{0}^{(0)} S_{j}^{(1)}\right]$,

c. co-operative manoeuvres: $\left[\left[_{0}^{[(1)} s_{j}^{(1)}\right]\right.$, 
C. encounter of the ships: $\left[S_{0}^{(-1)} S_{j}^{(-1)}\right]$,

D. situations of a unilateral dynamic game: $\left[S_{0}^{(-1)} S_{j}^{(0)}\right]$ and $\left[S_{0}^{(0)} S_{j}^{(-1)}\right]$,

Dangerous situations resulting from a faulty assessment of the approaching process by one of the parties with the other party's failure to conduct observation - one ship is equipped with a radar or an anti-collision system, the other with a damaged radar or without this device.

E. chasing situations which refer to a typical conflicting differential game: $\left[S_{0}^{(-1)} S_{j}^{(1)}\right]$ and $\left[S_{0}^{(1)} S_{j}^{(-1)}\right]$.

The first case usually represents regular optimal control, the second and third are unilateral games while the fourth and fifth cases represent the conflicting games [1-7].

\section{Conclusion}

The application of simplified models of the dynamic game of the process to the synthesis of the optimal control allows the determination of the object's safe trajectory in situations of passing a greater number of the encountered objects as a certain sequence of the course and speed manoeuvres. The developed software takes also into consideration the Rules of the Regulations for Preventing Collision at Sea COLREG and the advance time of the manoeuvre approximating the object's dynamic properties and evaluates the final deviation of the real trajectory from the assumed value. The considered steering algorithms are, in a certain sense, formal models of the thinking processes of a navigator conducting a maritime object and making manoeuvring decisions. They may be applied in the construction of both appropriate training simulators at the maritime educational centres and also for various options of the basic module of the ARPA anti-collision system.

\section{References}

1. Lisowski J (2018) Cooperative and non-cooperative game control strategies of the ship in collision situation. TransNav-The International Journal on Marine Navigation and Safety of Sea Transportation 12(1): 83-91.

2. Lisowski J (2017) Game control of maritime objects. Journal of Marine Engineering and Technology 16(4): 101-112.

3. Lisowski J (2016) The sensitivity of state differential game vessel traffic model. Polish Maritime Research 23 2(90): 14-18.

4. Lisowski J (2015) Multi-stage safe ship control with neural state constraints. Proceedings 2015 IEEE $2^{\text {nd }}$ International Conference on Cybernetics (CYBCONF), Gdynia, Poland.

5. Lisowski J (2014) Optimization-supported decision-making in the marine game environment. Solid State Phenomena, Trans Tech Publications, Switzerland 210: 215-222.

6. Lisowski J (2013) Sensitivity of computer support game algorithms of a safe ship control. International Journal of Applied Mathematics and Computer Science 23(2): 439-446.

7. Lisowski J (2012) Game control methods in avoidance of ships collisions. Polish Maritime Research 19(74): 3-10.

\section{Your next submission with Juniper Publishers will reach you the below assets}

- Quality Editorial service

- Swift Peer Review

- Reprints availability

- E-prints Service

- Manuscript Podcast for convenient understanding

- Global attainment for your research

- Manuscript accessibility in different formats

( Pdf, E-pub, Full Text, Audio)

- Unceasing customer service

Track the below URL for one-step submission https://juniperpublishers.com/online-submission.php 